\title{
Non-Neoplastic Nasal Cavity Disorder
}

National Cancer Institute

\section{Source}

National Cancer Institute. Non-Neoplastic Nasal Cavity Disorder. NCI Thesaurus. Code C27658.

A non-neoplastic disorder that affects the nasal cavity. Representative examples include rhinitis and Wegener granulomatosis. 